\title{
BMJ Open Influence of alcohol use on mortality and expenditure during hospital admission: a cross-sectional study
}

\author{
Shu-Hui Peng, ${ }^{1,2}$ Shiun-Yuan Hsu, ${ }^{3}$ Pao-Jen Kuo, ${ }^{2}$ Cheng-Shyuan Rau, ${ }^{4}$ \\ Ya-Ai Cheng, ${ }^{1}$ Ching-Hua Hsieh ${ }^{3}$
}

To cite: Peng S-H, Hsu S-Y, Kuo P-J, et al. Influence of alcohol use on mortality and expenditure during hospital admission: a cross-sectional study. BMJ Open 2016;6: e013176. doi:10.1136/ bmjopen-2016-013176

- Prepublication history for this paper is available online. To view these files please visit the journal online (http://dx.doi.org/10.1136/ bmjopen-2016-013176).

Y-AC and C-HH contributed equally.

Received 24 June 2016 Accepted 12 October 2016

CrossMark

For numbered affiliations see end of article.

Correspondence to Dr Ching-Hua Hsieh; m93chinghua@gmail.com

\section{ABSTRACT}

Objectives: This study was designed to investigate the effect of alcohol intoxication on clinical presentation of hospitalised adult trauma patients at a Level I trauma centre using propensity score matching.

Design: Cross-sectional study.

Setting: Taiwan.

Participants: Detailed data of 929 hospitalised adult trauma patients with alcohol intoxication, aged 20-65 years, and 10104 corresponding patients without alcohol intoxication were retrieved from the Trauma Registry System between 1 January 2009 and 31 December 2014. Alcohol intoxication was defined as a blood alcohol concentration (BAC) $\geq 50 \mathrm{mg} / \mathrm{dL}$.

Main outcome measures: In-hospital mortality and expenditure.

Results: Patients with alcohol intoxication presented with significantly higher short-term mortality (OR: 3.0 , $95 \% \mathrm{Cl} 2.0$ to $4.4 ; \mathrm{p}<0.001$ ) than patients without alcohol intoxication. However, on comparison with propensity score-matched patients with respect to sex, age, comorbidity, Glasgow Coma Scale (GCS), injury region based on Abbreviated Injury Scale (AIS) and Injury Severity Score (ISS), alcohol intoxication did not significantly influence mortality (OR: 0.8, 95\% Cl 0.5 to $1.4 ; p=0.563)$. This implied that the higher mortality of alcohol-intoxicated patients was attributable to patient characteristics such as a higher injury severity rather than alcohol intoxication. Even on comparison with sex-matched, age-matched and comorbidity-matched patients without alcohol intoxication, patients with alcohol intoxication still had significantly higher total expenditure $(17.4 \%$ higher), cost of operation (40.3\% higher), cost of examination (52.8\% higher) and cost of pharmaceuticals (38.3\% higher).

Conclusions: The associated higher mortality of adult trauma patients with alcohol intoxication was completely attributable to other patient characteristics and associated injury severity rather than the effects of alcohol. However, patients with alcohol intoxication incurred significantly higher expenditure than patients without alcohol intoxication, even on comparison with sex-matched, age-matched and comorbidity-matched patients without alcohol intoxication.

\section{Strengths and limitations of this study}

- Use of propensity score matching in this assess ment helped to attenuate the confounding effects of various patient characteristics and associated injury severity on hospital mortality and expenditure.

- Defining the cut-off value for alcohol intoxication at an arbitrary blood alcohol concentration (BAC) level of $50 \mathrm{mg} / \mathrm{dL}$ and higher may present a bias in the comparison between patients with and without alcohol intoxication; the definition of alcohol intoxication (BAC level) varies by country, and cognitive function may be impaired even at a lower BAC level.

- Bias in this analysis may result from a lack of available data in the following areas: indication of hospitalisation, type of surgery, patient costs associated with a referring hospital, circumstances of the injuries and factors influencing decision-making.

\section{BACKGROUND}

Alcohol consumption increases the likelihood of injury during activities. ${ }^{1-3}$ Consumption of three to four alcoholic drinks and five to six alcoholic drinks during the 6 hours preceding an accident led to a sixfold and a ninefold increase in the odds of injury, respectively. ${ }^{4}$ A previous case-control study ${ }^{5}$ and a case-crossover study, which compares injury between when patients drink before the event and when patients drink during an earlier control period, ${ }^{6}$ were conducted in emergency-room settings to estimate the risk of injury related to alcohol consumption. These studies revealed a 2.1-fold and 4.7-fold increase, respectively, in drinking-related injury. ${ }^{7}$ A multilevel analysis of 28 studies from 16 countries included 8423 patients with alcohol-related injuries who arrived in the emergency department (ED) within 6 hours of injury and showed that the overall prevalence of alcohol-related injuries was $24 \%$ for 
patients with a blood alcohol concentration (BAC) of $\geq 50 \mathrm{mg} / \mathrm{dL}^{8}$ An alcohol intoxication prevalence of 18 $80 \%$ has been reported at the time of admission, depending on the study design and inclusion criteria. ${ }^{9-12}$

In trauma patients, alcohol intoxication is associated with higher impact speed, ${ }^{13-15}$ which leads to higher injury severity ${ }^{10} 131617$ and mortality. ${ }^{13} 14$ The relative risk of involvement in a fatal vehicle crash increases with increasing BAC of the driver in every age/gender group among fatally injured and surviving drivers. ${ }^{1}$ Among 16-20-year-old male drivers, a BAC increase of $0.02 \%$ was estimated to more than double the relative risk of fatal single-vehicle crash injury. ${ }^{1}$ In addition, a previous study has reported that the mortality rate associated with traffic crashes doubled in patients with alcohol intoxication as compared to that of sober patients. ${ }^{13}$ In the USA, alcohol-impaired driving crashes account for nearly 11000 crash fatalities, or approximately one-third of all crash fatalities. ${ }^{18} 19$ A total of $35.2 \%$ of deaths worldwide were attributable to alcohol consumption in 2012, which resulted in $30.8 \%$ of disability-adjusted life years (DALYs) from injuries. ${ }^{20}$

Acute intoxication and dependence on alcohol are both associated with frequent utilisation of healthcare resources. $^{21}{ }^{22}$ National and international statistics on alcohol-related harm tend to emphasise estimates of the total numbers of deaths ${ }^{23}$ or total economic $\operatorname{costs}^{24}$ but rarely report the financial expenditure of healthcare per episode of injury. The effect of alcohol intoxication on the expenditure of caring for injured patients has important implications for trauma care and healthcare policy. Increased resource use and expenditure have been reported in a subset of minimally injured trauma patients who were BAC positive in trauma centres nationwide. ${ }^{25}{ }^{26}$ In medical evaluations, physicians often use advanced techniques to rule out the presence of potentially unidentified injuries in drunken patients. ${ }^{27}$ Alcohol-intoxicated patients had significantly higher chances of undergoing evaluation by abdominal ultrasound and head CT during the first 24 hours of hospital arrival. ${ }^{21}$ In alcohol-intoxicated patients with less-severe injuries, brain CT was overused, with a higher proportion of negative findings for intracranial haemorrhage. ${ }^{22}$ In an analysis of the sample of ED patient visits, representing 13 million ED visits nationwide, BAC-positive patients underwent more diagnostic tests and had longer ED stays. ${ }^{28}$

Previous studies have reported alcohol use to be associated with higher hospital mortality and expenditure. Since the patient's behaviour, the severity of the injury caused by the accident, and the response of the body to the traumatic injury are all influenced by alcohol, it is important to consider the differences in patient population in this assessment. In particular, alcohol has been reported to negatively influence the body's response to injury. ${ }^{29}$ For example, some studies demonstrated a beneficial effect of alcohol on patients with traumatic brain injury, ${ }^{30-32}$ although the exact mechanism is unclear. In addition, a positive serum alcohol level was associated with a significantly lower pneumonia rate in patients with isolated, moderate-to-severe traumatic brain injury and may explain the observed reduced mortality. ${ }^{33}$ In contrast, observational studies have shown that an elevated BAC is associated with an increased susceptibility to pneumonia, infections ${ }^{34}$ and the development of adult respiratory distress syndrome. ${ }^{35}$ Therefore, by using propensity score matching to attenuate the confounding effects of various patient characteristics and associated injury severity, this study was designed to assess the effect of alcohol intoxication on clinical presentation of hospitalised adult trauma patients in a Level I trauma centre in Southern Taiwan.

\section{METHODS}

\section{Ethics statement}

This study was preapproved by the Institutional Review Board (IRB) of the Chang Gung Memorial Hospital (approval number 104-8665B). Informed consent was waived according to IRB regulations.

\section{Study design}

This retrospective study reviewed data of all 20106 hospitalised patients registered in the Trauma Registry System from 1 January 2009 to 31 December 2014 (figure 1). The hospital is a 2400-bed facility and Level I regional trauma centre that provides care to trauma patients primarily from Southern Taiwan. All adult patients aged 20-65 years and hospitalised for treatment of traumatic injuries were included in the study. Patients who had incomplete registered data $(n=182)$ or lacked information on hospital expenditure $(n=3289)$ were excluded. In Taiwan, all drivers involved in traffic accidents are legally compelled to undergo testing for BAC. In trauma injuries other than traffic accidents, the physician at the ED may perform a BAC test when required or under strong suspicion. A BAC level of $50 \mathrm{mg} / \mathrm{dL}$, which is the legal limit for drivers in Taiwan, was defined as the cut-off value. Therefore, patients with a BAC level $\geq 50 \mathrm{mg} / \mathrm{dL}$ at the time of arrival at the hospital were considered intoxicated and were included in the study as BAC (+). Patients for whom an alcohol test was not requested or who had a $\mathrm{BAC}$ level $<50 \mathrm{mg} / \mathrm{dL}$ at the time of arrival at the hospital were considered to be nonintoxicated and BAC (-). Of the total 11033 adult patients, $929(8.4 \%)$ patients with BAC $(+)$ and 10104 $(91.6 \%)$ patients with BAC $(-)$ were enrolled in this study for further analysis. Detailed patient information was retrieved from the Trauma Registry System of our institution, including data on age; gender; trauma mechanism; initial Glasgow Coma Scale (GCS) in the ED; Abbreviated Injury Scale (AIS) severity score for each body region; Injury Severity Score (ISS); rates of associated injures; number of operations; hospital length of stay (LOS); LOS in intensive care unit (ICU); in-hospital mortality and total expenditure per patient including 
Figure 1 Flow chart of the studied adult trauma patients. BAC, blood alcohol concentration.

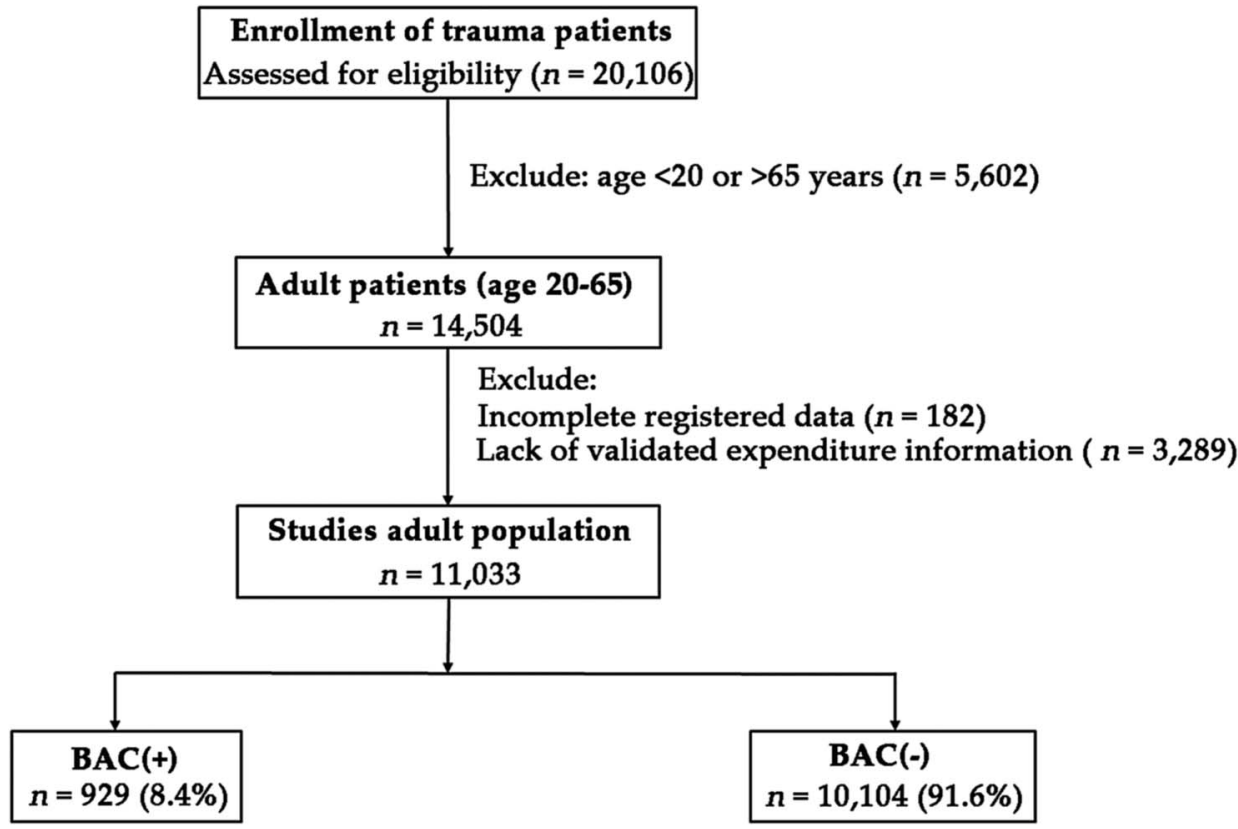

cost of operation (operation fee and operation supply fee), cost of examination (physical examination fee, haematology testing fee, examination fee for radiography, pathological examination fee, examination fee for electrocardiography, echo, endoscopy, electromyography, cardiac catheterisation and monitoring fee for electroencephalography), cost of pharmaceuticals (medicine service fee, medicine fee and narcotic drug fee) and other costs (registration fee, administrative fee, ward fees, nursing fee, blood/plasma test fees, haemodialysis fees, anaesthesia fees, rehabilitation-treatment fee, special material costs and personal expenses). The ISS is expressed as the median and IQR (Q1-Q3). Pre-existing comorbidities and chronic diseases including diabetes mellitus (DM), hypertension (HTN), coronary artery diseases $(\mathrm{CAD})$, congestive heart failure $(\mathrm{CHF})$, cerebrovascular accident (CVA) and end-stage renal disease (ESRD) were also identified. Odd ratios of the associated conditions and injuries of the patients were calculated with $95 \%$ CIs. The data collected were compared using IBM SPSS Statistics for Windows, V.20.0 (IBM, Armonk, New York, USA). Two-sided Fisher's exact or Pearson $\chi^{2}$ test was used to compare categorical data. Unpaired Student's t-test was used to analyse normally distributed continuous data, which were reported as mean \pm SD. Mann-Whitney U test was used to compare non-normally distributed data. To minimise confounding effects due to non-randomised assignment in the assessment of the effect of alcohol intoxication on mortality, propensity scores were calculated using a logistic regression model and the following covariates: gender, age, comorbidity, GCS, injuries based on AIS and ISS. A 1:1 matched study group was created by the Greedy method using NCSS software (NCSS V.10; NCSS Statistical software, Kaysville, Utah, USA). After adjusting for these confounding factors, binary logistic regression was used for evaluating the effect of intervention for alcohol intoxication on mortality. In addition, to assess the effect of alcohol intoxication on cost and number of surgeries, two comparable populations of BAC (+) and BAC (-) patients were selected in a 1:4 ratio by the Greedy method using NCSS software, according to the matched propensity scores, which were calculated using a logistic regression model with gender, age and comorbidity as covariates. p Values $<0.05$ were considered statistically significant.

\section{RESULTS}

Injury characteristics of patients with alcohol intoxication A significant predominance in the percentage of men was noted among patients with alcohol intoxication (821 $(88.4 \%)$ men and $108(11.6 \%)$ women of total 929 patients with alcohol intoxication). The mean ages of the patients with alcohol intoxication and those without alcohol intoxication were $40.4 \pm 11.5$ and $43.0 \pm 13.6$ years, respectively (table 1). Among patients with alcohol intoxication, a greater number of patients were aged 3039 and 40-49 years, but fewer patients were aged between 50-59 and 60-69 years. A greater number of patients with alcohol intoxication were younger than those without alcohol intoxication. Significantly lower incidence of pre-existing comorbidities and chronic diseases including HTN (OR: $0.7,95 \%$ CI 0.6 to 0.8 ; $\mathrm{p}<0.001$ ), DM (OR: $0.5,95 \%$ CI 0.3 to $0.6 ; \mathrm{p}<0.001$ ) and ESRD (OR: $0.2,95 \%$ CI 0.1 to $0.7 ; p=0.009$ ) were found among patients with alcohol intoxication as compared to those without alcohol intoxication. On comparison with patients without alcohol intoxication, patients with alcohol intoxication and those involved in motorcycle accidents were most commonly admitted $(48.5 \%$ vs $66.0 \%$, respectively; $\mathrm{p}<0.001)$, followed by strike by/ against objects $(25.0 \%$ vs $11.8 \%$, respectively; $\mathrm{p}<0.001)$, fall accidents $(19.9 \%$ vs $10.0 \%$, respectively; $\mathrm{p}<0.001)$ 
Table 1 Demographics and injury characteristics of the adult trauma patients with and without alcohol intoxication

\begin{tabular}{|c|c|c|c|c|}
\hline Variables & $\begin{array}{l}\text { BAC (+) } \\
\mathrm{N}=929\end{array}$ & $\begin{array}{l}\text { BAC (-) } \\
N=10104\end{array}$ & OR $(95 \% \mathrm{Cl})$ & p Value \\
\hline \multicolumn{5}{|l|}{$\overline{S e x}$} \\
\hline Male & $821(88.4)$ & $6113(60.5)$ & 5.0 (4.0 to 6.1$)$ & $<0.001$ \\
\hline Female & $108(11.6)$ & 3991 (39.5) & $0.2(0.2$ to 0.2$)$ & $<0.001$ \\
\hline Age (years) & $40.4 \pm 11.5$ & $43.0 \pm 13.6$ & - & $<0.001$ \\
\hline $20-29$ & $197(21.2)$ & $2302(22.8)$ & $0.9(0.8$ to 1.1$)$ & 0.287 \\
\hline 30-39 & $242(26.0)$ & 1847 (18.3) & $1.6(1.3$ to 1.8$)$ & $<0.001$ \\
\hline $40-49$ & 262 (28.2) & 1986 (19.7) & $1.6(1.4$ to 1.9$)$ & $<0.001$ \\
\hline $50-59$ & $181(19.5)$ & 2656 (26.3) & $0.7(0.6$ to 0.8$)$ & $<0.001$ \\
\hline $60-64$ & $47(5.1)$ & 1313 (13.0) & $0.4(0.3$ to 0.5$)$ & $<0.001$ \\
\hline \multicolumn{5}{|l|}{ Comorbidity } \\
\hline DM & $41(4.4)$ & $923(9.1)$ & $0.5(0.3$ to 0.6$)$ & $<0.001$ \\
\hline HTN & $102(11.0)$ & $1546(15.3)$ & $0.7(0.6$ to 0.8$)$ & $<0.001$ \\
\hline CAD & $6(0.6)$ & $124(1.2)$ & $0.5(0.2$ to 1.2$)$ & 0.150 \\
\hline $\mathrm{CHF}$ & $2(0.2)$ & $27(0.3)$ & $0.8(0.2$ to 3.4$)$ & 1.000 \\
\hline CVA & $5(0.5)$ & $127(1.3)$ & $0.4(0.2$ to 1.0$)$ & 0.057 \\
\hline ESRD & $3(0.3)$ & $138(1.4)$ & $0.2(0.1$ to 0.7$)$ & 0.009 \\
\hline Alcohol level (mg/dL) & $191.1 \pm 74.6$ & $15.5 \pm 15.0$ & - & - \\
\hline \multicolumn{5}{|l|}{ Mechanism } \\
\hline Motor vehicle & $66(7.1)$ & $269(2.7)$ & 2.8 (2.1 to 3.7$)$ & $<0.001$ \\
\hline Motorcycle & $613(66.0)$ & $4900(48.5)$ & 2.1 (1.8 to 2.4$)$ & $<0.001$ \\
\hline Bicycle & $29(3.1)$ & $260(2.6)$ & $1.2(0.8$ to 1.8$)$ & 0.333 \\
\hline Pedestrian & $18(1.9)$ & 135 (1.3) & $1.5(0.9$ to 2.4$)$ & 0.141 \\
\hline Fall & $93(10.0)$ & 2010 (19.9) & $0.4(0.4$ to 0.6$)$ & $<0.001$ \\
\hline Strike by/against & $110(11.8)$ & $2530(25.0)$ & $0.4(0.3$ to 0.5$)$ & $<0.001$ \\
\hline GCS & $12.6 \pm 3.7$ & $14.5 \pm 1.9$ & - & $<0.001$ \\
\hline$\leq 8$ & $158(17.0)$ & 337 (3.3) & 5.9 (4.9 to 7.3$)$ & $<0.001$ \\
\hline$\overline{9}-12$ & $122(13.1)$ & $248(2.5)$ & 6.0 (4.8 to 7.5$)$ & $<0.001$ \\
\hline$\geq 13$ & 649 (69.9) & 9519 (94.2) & 0.1 (0.1 to 0.2$)$ & $<0.001$ \\
\hline \multicolumn{5}{|l|}{ AIS } \\
\hline Head/neck & 485 (52.2) & 2184 (21.6) & 4.0 (3.5 to 4.5$)$ & $<0.001$ \\
\hline Face & $373(40.2)$ & 1646 (16.3) & 3.4 (3.0 to 4.0$)$ & $<0.001$ \\
\hline Thorax & $184(19.8)$ & $1183(11.7)$ & 1.9 (1.6 to 2.2$)$ & $<0.001$ \\
\hline Abdomen & $117(12.6)$ & $642(6.4)$ & $2.1(1.7$ to 2.6$)$ & $<0.001$ \\
\hline Extremity & $538(57.9)$ & 7430 (73.5) & $0.5(0.4$ to 0.6$)$ & $<0.001$ \\
\hline ISS (median, IQR) & $10(5.17)$ & $5(4.9)$ & - & $<0.001$ \\
\hline$<16$ & $626(67.4)$ & $8905(88.1)$ & $0.3(0.2$ to 0.3$)$ & $<0.001$ \\
\hline $16-24$ & 209 (22.5) & $822(8.1)$ & 3.3 (2.8 to 3.9$)$ & $<0.001$ \\
\hline$\geq 25$ & $94(10.1)$ & 377 (3.7) & 2.9 (2.3 to 3.7$)$ & $<0.001$ \\
\hline Mortality & $33(3.6)$ & $124(1.2)$ & 3.0 (2.0 to 4.4$)$ & $<0.001$ \\
\hline LOS in hospital (days) & $11.4 \pm 11.2$ & $9.1 \pm 10.0$ & - & $<0.001$ \\
\hline ICU admission, $\mathrm{n}(\%)$ & $329(35.4)$ & $1517(15.0)$ & 3.1 (2.7 to 3.6$)$ & $<0.001$ \\
\hline LOS in ICU (days) & $7.1 \pm 8.5$ & $9.4 \pm 12.1$ & - & $<0.001$ \\
\hline
\end{tabular}

AIS, Abbreviated Injury Scale; BAC, blood alcohol concentration; CAD, coronary artery disease; CHF, congestive heart failure; CVA, cerebral vascular accident; DM, diabetes mellitus; ESRD, end-stage renal disease; GCS, Glasgow Coma Scale; HTN, hypertension; ICU, intensive care unit; ISS, Injury Severity Score; LOS, length of stay.

and motor vehicle accidents $(2.7 \%$ vs $7.1 \%$, respectively; $\mathrm{p}<0.001)$. More patients with alcohol intoxication were injured in motorcycle and motor vehicle accidents than those without alcohol intoxication. In contrast, a smaller number of patients with alcohol intoxication were injured in strike by/against objects and fall accidents.

Injury severity of the patients with alcohol intoxication GCS were significantly lower (by 1 point) in patients with alcohol intoxication than in patients without alcohol intoxication $(12.6 \pm 3.7$ vs $14.5 \pm 1.9, \quad \mathrm{p}<0.001)$. A significantly larger number of patients with alcohol intoxication had a GCS of $\leq 8$ and GCS of 9-12 and a smaller number of patients had a GCS of $\geq 13$ compared to those without alcohol intoxication. Analysis of AIS revealed that patients with alcohol intoxication had sustained significantly higher rates of head/neck, face, thoracic and abdomen injuries than patients without alcohol intoxication, whereas patients without alcohol intoxication had sustained significantly 
higher rates of extremity injury. Regarding the associated common injuries in each trauma region, a significantly higher percentage of patients with alcohol intoxication had sustained associated common major injuries of head, maxillofacial, thoracic, abdominal and extremity trauma (table 2). In contrast, a significantly lower percentage of patients with alcohol intoxication had sustained humeral fracture and ulnar fracture. In addition, a significantly higher ISS was found in patients with alcohol intoxication than in patients without alcohol intoxication (median (IQR: Q1-Q3), 10 (5-17) vs $5(4-9), \mathrm{p}<0.001$ ) (table 1 ). When stratified by ISS $(<16,16-24$, or $\geq 25)$, among patients with alcohol intoxication, a larger number of patients had an ISS $\geq 25$ and an ISS of 16-24 and a smaller number of patients had an ISS $<16$ as compared to patients without alcohol intoxication.

\section{Outcome of patients with alcohol intoxication}

Patients with alcohol intoxication had a significantly higher mortality than those without alcohol intoxication (OR 3.0,
95\% CI 2.0 to $4.4 ; \mathrm{p}<0.001)$. After propensity score matching, mortality outcome was compared in the 131 wellbalanced pairs of patients (table 3). In these propensity score-matched patients, there was no significant difference in sex, age, comorbidity (HTN, DM and ESRD), GCS, injury region based on AIS and ISS. The logistic regression analysis showed that alcohol intoxication did not significantly influence mortality (OR: $0.8,95 \%$ CI 0.5 to 1.4 , $\mathrm{p}=0.563$ ), implying that the higher mortality of alcohol-intoxicated patients was attributable to the patient characteristics and associated with higher injury severity. Furthermore, compared to the patients without alcohol intoxication, the patients with alcohol intoxication had significantly longer hospital LOS (9.1 vs 11.4 days, respectively, $\mathrm{p}<0.001)$, higher proportion of patients admitted to the ICU $(15.0 \%$ vs $35.4 \%$, respectively, $\mathrm{p}<0.001)$ and shorter LOS in the ICU (9.4 vs 7.1 days, respectively, $\mathrm{p}<0.001$ ).

\section{Expenditure for patients with alcohol intoxication}

To compare the expenditure for patients with and those without alcohol intoxication, 929 well-balanced pairs of

Table 2 Significant associated injuries among the adult trauma patients with and without alcohol intoxication

\begin{tabular}{|c|c|c|c|c|}
\hline Variables & $\begin{array}{l}\text { BAC (+) } \\
\mathrm{N}=929\end{array}$ & $\begin{array}{l}\text { BAC (-) } \\
N=10104\end{array}$ & OR $(95 \% \mathrm{Cl})$ & p Value \\
\hline \multicolumn{5}{|l|}{ Head trauma, n (\%) } \\
\hline Neurologic deficit & $35(3.8)$ & $181(1.8)$ & $2.1(1.5$ to 3.1$)$ & $<0.001$ \\
\hline Cranial fracture & $150(16.1)$ & $482(4.8)$ & 3.8 (3.2 to 4.7$)$ & $<0.001$ \\
\hline $\mathrm{EDH}$ & $98(10.5)$ & $298(2.9)$ & 3.9 (3.1 to 4.9$)$ & $<0.001$ \\
\hline $\mathrm{SDH}$ & $180(19.4)$ & $630(6.2)$ & 3.6 (3.0 to 4.3 ) & $<0.001$ \\
\hline $\mathrm{SAH}$ & $186(20.0)$ & $716(7.1)$ & 3.3 (2.7 to 3.9$)$ & $<0.001$ \\
\hline $\mathrm{ICH}$ & $43(4.6)$ & $150(1.5)$ & 3.2 (2.3 to 4.6$)$ & $<0.001$ \\
\hline Cerebral contusion & $89(9.6)$ & $407(4.0)$ & 2.5 (2.0 to 3.2$)$ & $<0.001$ \\
\hline \multicolumn{5}{|l|}{ Maxillofacial trauma, n (\%) } \\
\hline Orbital fracture & $53(5.7)$ & $173(1.7)$ & 3.5 (2.5 to 4.8$)$ & $<0.001$ \\
\hline Nasal fracture & $25(2.7)$ & $101(1.0)$ & 2.7 (1.8 to 4.3$)$ & $<0.001$ \\
\hline Maxillary fracture & $147(15.8)$ & $557(5.5)$ & 3.2 (2.6 to 3.9$)$ & $<0.001$ \\
\hline Mandibular fracture & $47(5.1)$ & $217(2.1)$ & 2.4 (1.8 to 3.4$)$ & $<0.001$ \\
\hline \multicolumn{5}{|l|}{ Thoracic trauma, n (\%) } \\
\hline Rib fracture & $122(13.1)$ & $825(8.2)$ & $1.7(1.4$ to 2.1$)$ & $<0.001$ \\
\hline Haemothorax & $27(2.9)$ & $158(1.6)$ & 1.9 (1.2 to 2.9$)$ & 0.004 \\
\hline Pneumothorax & $23(2.5)$ & $154(1.5)$ & $1.6(1.1$ to 2.6$)$ & 0.030 \\
\hline Haemopneumothorax & $21(2.3)$ & $140(1.4)$ & 1.6 (1.0 to 2.6$)$ & 0.044 \\
\hline Lung contusion & $20(2.2)$ & $107(1.1)$ & 2.1 (1.3 to 3.3$)$ & 0.005 \\
\hline \multicolumn{5}{|l|}{ Abdominal trauma, $\mathrm{n}(\%)$} \\
\hline Intra-abdominal injury & $35(3.8)$ & $163(1.6)$ & $2.4(1.6$ to 3.5$)$ & $<0.001$ \\
\hline Hepatic injury & $55(5.9)$ & $166(1.6)$ & 3.8 (2.8 to 5.2 ) & $<0.001$ \\
\hline Splenic injury & $20(2.2)$ & $96(1.0)$ & 2.3 (1.4 to 3.7$)$ & 0.002 \\
\hline Renal injury & $10(1.1)$ & $47(0.5)$ & 2.3 (1.2 to 4.6$)$ & 0.019 \\
\hline \multicolumn{5}{|l|}{ Extremity trauma, n (\%) } \\
\hline Scapular fracture & $26(2.8)$ & $156(1.5)$ & 1.8 (1.2 to 2.8$)$ & 0.006 \\
\hline Clavicle fracture & $106(11.4)$ & $839(8.3)$ & $1.4(1.1$ to 1.8$)$ & 0.001 \\
\hline Humeral fracture & $21(2.3)$ & $482(4.8)$ & $0.5(0.3$ to 0.7$)$ & 0.001 \\
\hline Ulnar fracture & $34(3.7)$ & $525(5.2)$ & $0.7(0.5$ to 1.0$)$ & 0.042 \\
\hline Pelvic fracture & $38(4.1)$ & $276(2.7)$ & 1.5 (1.1 to 2.1$)$ & 0.019 \\
\hline Tibial fracture & $72(7.8)$ & $497(4.9)$ & 1.6 (1.3 to 2.1$)$ & $<0.001$ \\
\hline
\end{tabular}


Table 3 Covariates of the adult trauma patients with and without alcohol intoxication adjusted for 1:1 greedy propensity score matching for mortality assessment

\begin{tabular}{|c|c|c|c|c|c|c|c|c|}
\hline & \multicolumn{4}{|l|}{ Before } & \multicolumn{4}{|l|}{ After } \\
\hline & $\begin{array}{l}\text { Death } \\
n=157\end{array}$ & $\begin{array}{l}\text { Survival } \\
n=10876\end{array}$ & OR (95\% Cl) & p Value & $\begin{array}{l}\text { Death } \\
n=131\end{array}$ & $\begin{array}{l}\text { Survival } \\
n=131\end{array}$ & OR (95\% Cl) & p Valc \\
\hline \multicolumn{9}{|l|}{$\overline{\text { Sex }}$} \\
\hline Male & $122(77.7)$ & $6812(62.6)$ & 2.1 (1.4 to 3.0 ) & $<0.001$ & $111(84.7)$ & $111(84.7)$ & $1.0(0.5$ to 2.0$)$ & 1.000 \\
\hline Female & 35 (22.3) & 4064 (37.4) & 0.5 (0.3 to 0.7$)$ & $<0.001$ & $20(15.3)$ & 20 (15.3) & $1.0(0.5$ to 2.0$)$ & 1.000 \\
\hline Age & $46.7 \pm 13.5$ & $42.7 \pm 13.5$ & - & $<0.001$ & $45.8 \pm 13.5$ & $44.8 \pm 12.3$ & - & 0.560 \\
\hline \multicolumn{9}{|l|}{ Comorbidity } \\
\hline HTN & $23(14.6)$ & 1625 (14.9) & $1.0(0.6$ to 1.5$)$ & 1.000 & $19(14.5)$ & 19 (14.5) & $1.0(0.5$ to 2.0$)$ & 1.000 \\
\hline DM & $16(10.2)$ & $948(8.7)$ & $1.2(0.7$ to 2.0$)$ & 0.568 & $10(7.6)$ & $10(7.6)$ & $1.0(0.4$ to 2.5$)$ & 1.000 \\
\hline ESRD & $9(5.7)$ & $132(1.2)$ & 5.0 (2.5 to 9.9$)$ & $<0.001$ & $4(3.1)$ & $4(3.1)$ & $1.0(0.2$ to 4.1$)$ & 1.000 \\
\hline GCS & $7.2 \pm 4.8$ & $14.5 \pm 1.9$ & - & $<0.001$ & $7.5 \pm 4.8$ & $8.0 \pm 4.8$ & - & 0.418 \\
\hline \multicolumn{9}{|l|}{ AIS, n (\%) } \\
\hline Head/neck & $128(81.5)$ & 2541 (23.4) & 14.5 (9.7 to 21.7$)$ & $<0.001$ & $105(80.2)$ & $105(80.2)$ & $1.0(0.5$ to 1.8$)$ & 1.000 \\
\hline Face & $22(14.0)$ & 1997 (18.4) & $0.7(0.5$ to 1.1$)$ & 0.177 & $19(14.5)$ & $19(14.5)$ & $1.0(0.5$ to 2.0$)$ & 1.000 \\
\hline Thorax & 54 (34.4) & $1313(12.1)$ & 3.8 (2.7 to 5.3$)$ & $<0.001$ & $46(35.1)$ & $46(35.1)$ & $1.0(0.6$ to 1.7$)$ & 1.000 \\
\hline Abdomen & 26 (16.6) & $733(6.7)$ & 2.7 (1.8 to 4.2$)$ & $<0.001$ & $22(16.8)$ & $22(16.8)$ & $1.0(0.5$ to 1.9$)$ & 1.000 \\
\hline Extremity & $47(29.9)$ & 7921 (72.8) & $0.2(0.1$ to 0.2$)$ & $<0.001$ & $38(29.0)$ & $38(29.0)$ & $1.0(0.6$ to 1.7$)$ & 1.000 \\
\hline ISS & $30.8 \pm 17.8$ & $7.7 \pm 6.5$ & - & $<0.001$ & $27.0 \pm 13.3$ & $25.0 \pm 13.4$ & - & 0.247 \\
\hline $\mathrm{BAC}(+)$ & $33(21.0)$ & $896(8.2)$ & 3.0 (2.0 to 4.4$)$ & $<0.001$ & $29(22.1)$ & $34(26.0)$ & 0.8 (0.5 to 1.4$)$ & 0.563 \\
\hline
\end{tabular}

Mortality (OR: $0.81,95 \% \mathrm{Cl} 0.46$ to $1.432, \mathrm{p}=0.470$ ).

AIS, Abbreviated Injury Scale; BAC, blood alcohol concentration; DM, diabetes mellitus; ESRD, end-stage renal disease; GCS, Glasgow Coma Scale; HTN, hypertension; ISS, Injury Severity Score.

patients, with a 1:4 ratio after propensity score matching of sex, age and comorbidity (HTN, DM, and ESRD), were used for outcome assessment (table 4). In these propensity score-matched patients, there was no significant difference in sex, age and comorbidity (HTN, DM and ESRD). On comparison with patients without alcohol intoxication, those who had alcohol intoxication spent a significantly higher total expenditure $(28.3 \%$ higher), cost of operation (51.8\% higher), cost of examination $(71.7 \%$ higher) and cost of pharmaceuticals (63.8\% higher) (table 5). On comparing the selected well-balanced pairs of patients with and those without alcohol intoxication, who had similar personal characteristics regarding sex, age and comorbidities, those who had alcohol intoxication still had significantly higher total expenditure (17.4\% higher), cost of operation
(40.3\% higher), cost of examination (52.8\% higher) and cost of pharmaceuticals (38.3\% higher) (table 6).

\section{DISCUSSION}

This study compared the clinical outcome and expenditure in a broad group of adult trauma patients comprising those with alcohol intoxication and those without alcohol intoxication hospitalised at a Level I trauma centre. Patients with alcohol intoxication presented with significantly different body-injury patterns, higher injury severity, longer hospital stay, higher proportion of admission to the ICU and higher short-term mortality than those without alcohol intoxication. In addition, patients with alcohol intoxication had significantly higher total expenditure, cost of operation, cost of examination and

Table 4 Covariates of the adult trauma patients with and without alcohol intoxication adjusted for 1:4 greedy propensity score matching for cost assessment

\begin{tabular}{|c|c|c|c|c|c|c|c|c|}
\hline & \multicolumn{4}{|l|}{ Before } & \multicolumn{4}{|l|}{ After } \\
\hline & $\begin{array}{l}\text { BAC (+) } \\
n=929\end{array}$ & $\begin{array}{l}\text { BAC (-) } \\
n=10104\end{array}$ & OR (95\% Cl) & p Value & $\begin{array}{l}\text { BAC (+) } \\
n=929\end{array}$ & $\begin{array}{l}\text { BAC (-) } \\
n=3716\end{array}$ & OR $(95 \% \mathrm{Cl})$ & p Value \\
\hline \multicolumn{9}{|l|}{ Sex } \\
\hline Male & $821(88.4)$ & $6113(60.5)$ & $5.0(4.0$ to 6.1$)$ & $<0.001$ & $821(88.4)$ & $3284(88.4)$ & 1.0 (0.8 to 1.3$)$ & 1.000 \\
\hline Female & 108 (11.6) & 3991 (39.5) & 0.2 (0.2 to 0.2$)$ & $<0.001$ & 108 (11.6) & $432(11.6)$ & 1.0 (0.8 to 1.3$)$ & 1.000 \\
\hline Age & $40.4 \pm 11.5$ & $43.0 \pm 13.6$ & - & $<0.001$ & $40.4 \pm 11.5$ & $40.4 \pm 11.5$ & - & 0.989 \\
\hline \multicolumn{9}{|c|}{ Comorbidity } \\
\hline HTN & $102(11.0)$ & 1546 (15.3) & $0.7(0.6$ to 0.8$)$ & $<0.001$ & $102(11.0)$ & $408(11.0)$ & $1.0(0.8$ to 1.3$)$ & 1.000 \\
\hline DM & $41(4.4)$ & $923(9.1)$ & 0.5 (0.3 to 0.6$)$ & $<0.001$ & $41(4.4)$ & $164(4.4)$ & $1.0(0.7$ to 1.4$)$ & 1.000 \\
\hline ESRD & $3(0.3)$ & $138(1.4)$ & $0.2(0.1$ to 0.7$)$ & 0.009 & $3(0.3)$ & $12(0.3)$ & $1.0(0.3$ to 3.6$)$ & 1.000 \\
\hline
\end{tabular}


Table 5 The cost during the hospitalisation of the adult trauma patients with and without alcohol intoxication

\begin{tabular}{lllll}
\hline & BAC (+) & BAC $(-)$ & Difference & p Value \\
\hline Total expenditure (US\$) & $(n=929) 3656 \pm 5104$ & $(n=10104) 2850 \pm 4355$ & $28.3 \% \uparrow$ & $<0.001$ \\
Cost of operation (US\$) & $(n=601) 958 \pm 864$ & $(n=7558) 631 \pm 706$ & $51.8 \% \uparrow$ & $<0.001$ \\
Cost of examination (US\$) & $(n=791) 249 \pm 353$ & $(n=8474) 145 \pm 289$ & $71.7 \% \uparrow$ & $<0.001$ \\
Cost of pharmaceutical (US\$) & $(n=929) 285 \pm 773$ & $(n=10103) 174 \pm 859$ & $63.8 \% \uparrow$ & $<0.001$
\end{tabular}

Under the calculation of 33 New Taiwan Dollar (NTD) per US dollar

BAC, blood alcohol concentration.

Table 6 The cost during the hospitalisation of the selected propensity score-matched adult trauma patients with and without alcohol intoxication

\begin{tabular}{llllr}
\hline & BAC (+) & BAC (-) & Difference & p Value \\
\hline Total expenditure (US\$) & $(n=929) 3656 \pm 5104$ & $(n=3716) 3113 \pm 5278$ & $17.4 \% \uparrow$ & 0.004 \\
Cost of operation (US\$) & $(n=601) 958 \pm 864$ & $(n=2758) 683 \pm 860$ & $40.3 \% \uparrow$ & $<0.001$ \\
Cost of examination (US\$) & $(n=791) 249 \pm 353$ & $(n=3037) 163 \pm 336$ & $52.8 \% \uparrow$ & $<0.001$ \\
Cost of pharmaceutical (US\$) & $(n=929) 285 \pm 773$ & $(n=3715) 206 \pm 706$ & $38.3 \% \uparrow$ & 0.005 \\
\hline
\end{tabular}

Under the calculation of 33 New Taiwan Dollar (NTD) per US dollar.

BAC, blood alcohol concentration.

cost of pharmaceuticals than those without alcohol intoxication, regardless of whether the comparison was made among the total patients or among the selected propensity score-matched patients.

In this study, patients with alcohol intoxication were predominantly men, of younger age, and had lower incidence of pre-existing comorbidities and chronic diseases. In addition, patients with alcohol intoxication sustained significantly higher injury severity and rates of head/neck injury, face injury, thoracic injury and abdomen injury, but lower rate of extremity injury than patients without alcohol intoxication. In addition, the mortality was threefold higher in patients with alcohol intoxication than that of patients without alcohol intoxication. Notably, controlled experimental and epidemiologic studies have shown that alcohol exposure can increase the severity of injury, ${ }^{36}$ and the adjustment for injury severity in their analyses of outcomes from alcohol intoxication may have obscured the association of mortality and other outcomes with BAC. ${ }^{37}$ In this study, by analysing the selected propensity score-matched patients with respect to sex, age, comorbidity, GCS, and injury region based on AIS, and ISS, we found that alcohol intoxication did not significantly influence mortality; this implies that the higher mortality of these alcohol-intoxicated patients was attributable to the patient characteristics and associated higher injury severity. These results are in agreement with the results of some studies that stated that although the beneficial effects of alcohol have been controversial, ${ }^{38}$ its detrimental effects on injury outweigh its beneficial effects. ${ }^{23}$

In this study, compared to the patients without alcohol intoxication, the patients with alcohol intoxication had significantly longer hospital LOS (9.1 vs 11.4 days, respectively; $\mathrm{p}<0.001$ ), higher proportion of patients admitted to the ICU ( $15.0 \%$ vs $35.4 \%$, respectively; $\mathrm{p}<0.001$ ), but shorter LOS in the ICU (9.4 vs 7.1 days, respectively; $\mathrm{p}<0.001)$. Patients with alcohol intoxication had significantly higher total expenditure, cost of operation, cost of examination and cost of pharmaceuticals than the total patient population and the selected propensity score-matched patients with respect to sex, age and comorbidity. Multiple factors may have contributed to the increase in the expenditure of alcohol-intoxicated patients. In addition, more examinations, ${ }^{21} 2227$ excess charges for laboratory testing and radiologic testing, and extra monitoring and other procedures may be conducted for patients with alcohol intoxication. ${ }^{28}$ These alcohol-intoxicated patients were also more likely to have a delay in discharge due to alcohol withdrawal ${ }^{39}$ and require a high level of in-hospital care such as in a coronary care unit or ICU. $^{28}$ In contrast, previous studies have reported a reduction in the hospital LOS and lower overall costs of care associated with intoxicated patients. ${ }^{36}{ }^{40}$ However, the descriptive study design prevented further analysis of the effects of additional factors (eg, a particular treatment and the judgement of discharge from the hospital or stay in the ICU) and relied on the assumption of uniform assessment and management of patients with and without alcohol intoxication.

Our study has some limitations that should be acknowledged. First, owing to the retrospective design of the study with its inherent selection bias, it was impossible to fully account for potential confounders of important risk factors such as differentiation between alcohol-induced psychoses, alcohol dependence and alcohol abuse; ${ }^{41}$ between intentional and unintentional injuries and most importantly, between patterns of drinking and alcohol consumption. Second, the lack 
of data regarding indication of hospitalisation, type of surgery and the associated-patient costs at the referring hospital may have led to a bias. Third, the patients declared dead on hospital arrival or at the accident scene were not included in the Trauma Registry Database, and some outcomes such as late mortality were not analysed, which potentially led to bias in the assessment of mortality and overall cost. Further, in Taiwan, all drivers involved in traffic accidents are legally compelled to undergo BAC testing; however, a few patients may have refused to undergo an actual BAC test after alcohol consumption was confirmed using a breathalyser. Accordingly, these patients might have been placed in an incorrect category, because the breathalyser results were registered in the police report but not noted in the medical records. In addition, the combination of psychoactive drugs and alcohol use may have led to bias in the outcome assessment. ${ }^{42}$ However, in our experience, such cases are rare. Finally, considering that cognitive function may be impaired at a BAC level of $<50 \mathrm{mg} / \mathrm{dL}^{14}{ }^{43}$ and that the BAC level that defines alcohol intoxication varies by country, an arbitrary BAC cut-off value of $50 \mathrm{mg} / \mathrm{dL}$ as the definition of alcohol intoxication may have introduced bias into this study. Moreover, the most common traumatic injuries in Taiwan involved motorcycle accidents rather than car accidents, which are more common in Western countries; this may also hinder the generalisation of assessing the effect of alcohol intoxication on hospital mortality and expenditure.

\section{CONCLUSIONS}

This study of hospitalised adult trauma patients, based on the Trauma Registry System at a Level I trauma centre and spanning a 6-year period, revealed that a higher mortality associated with the adult trauma patients with alcohol intoxication was completely attributable to patient characteristics and associated injury severity and not to the effects of alcohol. However, patients with alcohol intoxication incurred significantly higher expenditure than patients without alcohol intoxication, even on comparison with sex-matched, agematched and comorbidity-matched patients without alcohol intoxication.

\section{Author affiliations \\ ${ }^{1}$ Executive Master Program, Department of Healthcare Administration, I-Shou University, Kaohsiung, Taiwan \\ ${ }^{2}$ Department of Plastic Surgery, Kaohsiung Chang Gung Memorial Hospital and Chang Gung University College of Medicine, Kaohsiung, Taiwan ${ }^{3}$ Department of Trauma Surgery, Kaohsiung Chang Gung Memorial Hospital and Chang Gung University College of Medicine, Kaohsiung, Taiwan ${ }^{4}$ Department of Neurosurgery, Kaohsiung Chang Gung Memorial Hospital and Chang Gung University College of Medicine, Kaohsiung, Taiwan}

Contributors S-HP analysed the data and wrote the manuscript; S-YH collected the data and performed the statistical analyses; P-JK validated and is responsible for the integrity of registered data; CSR edited the tables; Y-AC revised the manuscript and supervised the proceedings of the study and
C-HH designed the study and contributed to the analysis and interpretation of data. All authors read and approved the final manuscript.

Funding This research was supported by a grant (CMRPG8E1271).

Competing interests None declared.

Ethics approval Institutional Review Board of the Chang Gung Memorial Hospital.

Provenance and peer review Not commissioned; externally peer reviewed.

Data sharing statement No additional data are available.

Open Access This is an Open Access article distributed in accordance with the Creative Commons Attribution Non Commercial (CC BY-NC 4.0) license, which permits others to distribute, remix, adapt, build upon this work noncommercially, and license their derivative works on different terms, provided the original work is properly cited and the use is non-commercial. See: http:// creativecommons.org/licenses/by-nc/4.0/

\section{REFERENCES}

1. Zador PL, Krawchuk SA, Voas RB. Alcohol-related relative risk of driver fatalities and driver involvement in fatal crashes in relation to driver age and gender: an update using 1996 data. J Stud Alcohol 2000;61:387-95.

2. Taylor B, Irving HM, Kanteres F, et al. The more you drink, the harder you fall: a systematic review and meta-analysis of how acute alcohol consumption and injury or collision risk increase together. Drug Alcohol Depend 2010;110:108-16.

3. Liu HT, Liang CC, Rau CS, et al. Alcohol-related hospitalizations of adult motorcycle riders. World J Emerg Surg 2015;10:2.

4. Vinson DC, Maclure M, Reidinger C, et al. A population-based case-crossover and case-control study of alcohol and the risk of injury. J Stud Alcohol 2003;64:358-66.

5. Cherpitel CJ. Alcohol and injuries: a review of international emergency room studies. Addiction 1993;88:923-37.

6. Stockwell T, McLeod R, Stevens M, et al. Alcohol consumption, setting, gender and activity as predictors of injury: a population-based case-control study. J Stud Alcohol 2002;63:372-9

7. Ye Y, Bond J, Cherpitel CJ, et al. Risk of injury due to alcohol: evaluating potential bias using the case-crossover usual-frequency method. Epidemiology 2013;24:240-3.

8. Cherpitel $\mathrm{CJ}, \mathrm{Ye} \mathrm{Y}$, Bond $\mathrm{J}$, et al. Multi-level analysis of alcohol-related injury among emergency department patients: a cross-national study. Addiction 2005;100:1840-50.

9. Centers for Disease Control and Prevention (CDC). Alcohol and other drug use among victims of motor-vehicle crashes-West Virginia, 2004-2005. MMWR Morb Mortal Wkly Rep 2006;55:1293-6.

10. Fabbri A, Marchesini G, Morselli-Labate AM, et al. Positive blood alcohol concentration and road accidents. A prospective study in an Italian emergency department. Emerg Med J 2002;19:210-14

11. Schwan R, Allen JP. Unhealthy alcohol use. N Engl J Med 2005;352:2139-40. Author reply 39-40.

12. Borges G, Macdonald S, Cherpitel CJ, et al. Chapter 2: Variation in alcohol-related injury by type and cause of injury. In: Cherpitel $\mathrm{CJ}$, Borges G, Giesbrecht N, et al, eds. Alcohol and injuries: emergency department studies in an international perspective. Geneva, Switzerland: World Health Organization, 2009:15-25.

13. Stübig T, Petri M, Zeckey $C$, et al. Alcohol intoxication in road traffic accidents leads to higher impact speed difference, higher ISS and MAIS, and higher preclinical mortality. Alcohol 2012;46:681-6.

14. Phillips DP, Brewer KM. The relationship between serious injury and blood alcohol concentration (BAC) in fatal motor vehicle accidents: $\mathrm{BAC}=0.01 \%$ is associated with significantly more dangerous accidents than $\mathrm{BAC}=0.00 \%$. Addiction 2011:106:1614-22.

15. McCoy GF, Johnstone RA, Nelson IW, et al. A review of fatal road accidents in Oxfordshire over a 2-year period. Injury 1989;20:65-8.

16. Tulloh BR, Collopy BT. Positive correlation between blood alcohol level and ISS in road trauma. Injury 1994;25:539-43.

17. Pories SE, Gamelli RL, Vacek P, et al. Intoxication and injury. J Trauma 1992;32:60-4.

18. Scheyerer MJ, Dütschler J, Billeter A, et al. Effect of elevated serum alcohol level on the outcome of severely injured patients. Emerg Med J 2014;31:813-17. 
19. Centers for Disease Control and Prevention. Vital signs: alcohol-impaired driving among adults-United States, 2010. MMWR Morb Mortal Wkly Rep 2011;60:1351-6.

20. Gowing LR, Ali RL, Allsop C, et al. Global statistics on addictive behaviours: 2014 status report. Addiction 2015;110:904-19.

21. Roudsari B, Caetano R, Field C. Alcohol intoxication/dependence, ethnicity and utilisation of health care resources in a level I trauma center. Injury 2011;42:66-71.

22. Rau CS, Liu HT, Hsu SY, et al. Alcohol-related hospitalisations of trauma patients in Southern Taiwan: a cross-sectional study based on a trauma registry system. BMJ Open 2014;4:e005947.

23. Rehm J, Mathers C, Popova S, et al. Global burden of disease and injury and economic cost attributable to alcohol use and alcohol-use disorders. Lancet 2009;373:2223-33.

24. Kyu HH, Pinho C, Wagner JA, et al, Global Burden of Disease Pediatrics Collaboration. Global and National Burden of Diseases and Injuries among children and adolescents between 1990 and 2013: findings from the global burden of disease 2013 study. JAMA Pediatr 2016;170:267-87.

25. O'Keeffe T, Shafi S, Sperry JL, et al. The implications of alcohol intoxication and the Uniform Policy Provision Law on trauma centers a national trauma data bank analysis of minimally injured patients. J Trauma 2009;66:495-8.

26. Rivara FP, Koepsell TD, Jurkovich GJ, et al. The effects of alcohol abuse on readmission for trauma. JAMA 1993;270:1962-4.

27. Moore EE. Alcohol and trauma: the perfect storm. J Trauma 2005;59 (3 Suppl):S53-6. Discussion S67-75.

28. O'Keeffe T, Rhee P, Shafi S, et al. Alcohol use increases diagnostic testing, procedures, charges, and the risk of hospital admission: a population-based study of injured patients in the emergency department. Am J Surg 2013;206:16-22.

29. Guo R, Ren J. Alcohol and acetaldehyde in public health: from marvel to menace. Int J Environ Res Public Health 2010;7:1285-301.

30. Berry C, Salim A, Alban R, et al. Serum ethanol levels in patients with moderate to severe traumatic brain injury influence outcomes: a surprising finding. Am Surg 2010;76:1067-70.
31. Salim A, Teixeira P, Ley EJ, et al. Serum ethanol levels: predictor of survival after severe traumatic brain injury. J Trauma 2009;67:697-703.

32. Salim A, Ley EJ, Cryer HG, et al. Positive serum ethanol level and mortality in moderate to severe traumatic brain injury. Arch Surg 2009;144:865-71.

33. Hadjibashi AA, Berry C, Ley EJ, et al. Alcohol is associated with a lower pneumonia rate after traumatic brain injury. J Surg Res 2012;173:212-15

34. Ruiz M, Ewig S, Torres A, et al. Severe community-acquired pneumonia. Risk factors and follow-up epidemiology. Am J Respir Crit Care Med 1999;160:923-9.

35. Afshar M, Smith GS, Terrin ML, et al. Blood alcohol content, injury severity, and adult respiratory distress syndrome. J Trauma Acute Care Surg 2014;76:1447-55.

36. Jurkovich GJ, Rivara FP, Gurney JG, et al. The effect of acute alcohol intoxication and chronic alcohol abuse on outcome from trauma. JAMA 1993;270:51-6.

37. VanderWeele TJ. On the relative nature of overadjustment and unnecessary adjustment. Epidemiology 2009;20:496-9.

38. Fuchs FD, Chambless LE. Is the cardioprotective effect of alcohol real? Alcohol 2007;41:399-402.

39. Williams RJ, Hittinger R, Glazer G. Resource implications of head injuries on an acute surgical unit. J R Soc Med 1994;87: 83-6.

40. Fuller MG. Alcohol use and injury severity in trauma patients. $J$ Addict Dis 1995;14:47-54.

41. Murray CJ, Lopez AD. Quantifying disability: data, methods and results. Bull World Health Organ 1994;72:481-94.

42. Watt K, Purdie DM, Roche AM, et al. Risk of injury from acute alcohol consumption and the influence of confounders. Addiction 2004;99:1262-73.

43. Breitmeier D, Seeland-Schulze I, Hecker $\mathrm{H}$, et al. The influence of blood alcohol concentrations of around $0.03 \%$ on neuropsychological functions-a double-blind, placebo-controlled investigation. Addict Biol 2007;12:183-9. 